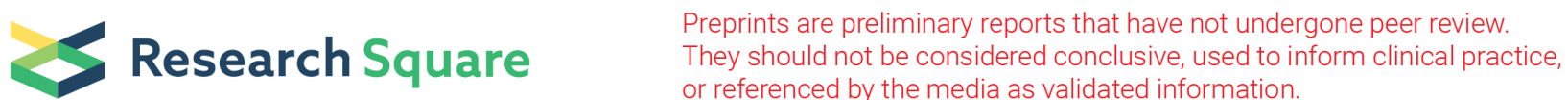

\section{Health Care Distribution of Patients With Genitourinary Birth Defects in Colombia: a Spatial Analysis of Registered Cases}

\author{
Jessica Santander \\ Fundación Santa Fe de Bogotá \\ Marcela Pérez-Sosa \\ Universidad Nacional de Colombia \\ Andrés Gutiérrez \\ Hospital Universitario San Ignacio, Pontificia Universidad Javeriana \\ Nicolas Femandez ( $\square$ nicolas.fernandez@seattlechildrens.org) \\ Seattle Childrens Hospital
}

\section{Research Article}

Keywords:

Posted Date: January 21st, 2022

DOI: https://doi.org/10.21203/rs.3.rs-1273849/v1

License: @ (1) This work is licensed under a Creative Commons Attribution 4.0 International License. Read Full License 


\section{Abstract}

Background: Genitourinary birth defects are reported to be present in approximately $10-30 \%$ of all newborns. Timely treatments may reduce complications that contribute to increased infant morbimortality. Understanding the distribution of health access is essential for the design of health interventions and resources distribution. We aim to evaluate geographical distribution in the healthcare access to subspecialized medical care of patients with genitourinary birth defects in Colombia.

Methods: We reviewed data collected between January 2015 to December 2019 in the Individual Health Records System (RIPS). All registered patients diagnosed with renal malformations, male genital malformations, and exstrophy-epispadias complex as well all registered live births were included. Cluster detection was performed using a Poisson model with SaTScan v9.6. To visualize the results, these were projected in a Google Earth map.

Results: Between January 2015 and December 2019 a total of 26.726 patients with renal malformations, 19.149 patients with genital malformations, and 494 patients with exstrophy-epispadias complex in the outpatient clinic were assessed in Colombian territory. A space-time analysis identified one cluster with high provided health care concentration seen in the center of the country for renal and genital malformations. Meanwhile northern regions close to the coast were identified as clusters with low rates of provided care regions. For cases with exstrophy-epispadias complex, regions in the north had lower registered assessments compared to the center of the country.

Conclusion: Patients with genitourinary malformations have inequitable access to specialized health care which can delay surgical management and impact long-term outcomes that increase disability.

\section{Introduction}

Genitourinary birth defects are reported to be present in approximately $10-30 \%$ of all newborns and can lead to varying degrees of morbimortality. $(1,2)$ Congenital kidney anomalies are responsible for up to $50 \%$ of chronic renal failure in children worldwide.(2) A cohort study conducted by Calderon-Margalit et al (3) found a hazard ratio of $4.19(95 \% \mathrm{Cl} 3.52-4.99)$ for end-stage renal disease (ESRD) in patients with a history of childhood kidney disease after 30 years of follow-up. Mild kidney abnormalities in childhood could be a risk factor for ESRD in adulthood, even there is no compromise of renal function at the time of diagnosis. (3) Similarly, Chu et al (4) followed a cohort of children survivors of Wilms tumor, founded abnormal ambulatory blood pressure monitoring in $76 \%$ of participants, masked hypertension in $34 \%$ and microalbuminuria in $6 \%$. Timely treatments may reduce complications that otherwise would contribute to increased infant morbidity and mortality with lifelong permanent disabilities. (5) On the other hand, congenital anomalies that affect genitals have a lifelong impact on multiple domains, including urinary function, sexuality, fertility, and psychosocial wellness. (6) In both scenarios, identification and timely management of cases are essential to positively impact prognosis.

According to Global Health Estimates (7), congenital anomalies were in the top 10 global causes of disability-adjusted life years (DALYs) in 2019. Despite the burden of these conditions dropped worldwide from 61.815 million DALYs in 2010 to 51.797 million DALYs in 2019 (8), still persists disparities between regions. Around $94 \%$ of congenital anomalies occur in low- and middle-income countries. (9) The large proportion of cases added to low coverage of surgical care in these settings, delay the access to timely treatment, which in turn increases the burden of disease. Delays related to presentation to medical care, referral for specialized care and surgery has been demonstrated be longest in lowincome country (Kenya) compared to high-income country (Canada). (10)

Spatial analysis has emerged as a practical tool for epidemiological research since it allows detecting spatial disparities in the occurrence of diseases. $(11,12)$ A spatial cluster is an unusual number of cases within a population in a time period. $(13)$ They can reveal trends that may not be apparent at an individual level, therefore, are useful for health services planning. (14) Understanding the distribution of health access is essential for the design of health interventions and resources distribution. The aim of the present study is to evaluate geographical distribution in the healthcare access to subspecialized medical care of patients with genitourinary birth defects in Colombia.

\section{Methods}

\section{Data collection}

Colombia is divided into 32 departments and 1119 municipalities. According to the 2018 national census, $77.1 \%$ of population lives in urban areas and approximately 25\% residing in four main cities (Bogotá, Medellín, Cali, and Barranquilla). (15) The central region is the territory where the largest population is located with equivalent to $70.1 \%$, where high complexity/specialized university hospitals area also located. Followed by $21.9 \%$ inhabit the north region, the $3 \%$ in the east and the remained in the west and the south $(2.7 \%$ and $2.4 \%$, respectively). (16)

The Individual health records system (Registros Individuales de Prestación de Servicios de Salud - RIPS, by its Spanish acronym) is a data repository for the management, regulation, and control processes for the health services required by the General System of Social Security in 
Colombia (17). Their aim is to follow up on the health services provided, evaluate service coverage, formulate health policies as well as allocate financial and human resources. The information must be organized according to guidelines proposed by the Ministry of Health. Data registration is mandatory and performed monthly by health-providing institutions and independent professionals. Data analysis reports are sent to insurers for validation and verification. Finally, records are consolidated and a report is generated. (17) Information is available for public consultation through an Open Database Connectivity (ODBC).

For the present study we reviewed data collected between January 2015 to December 2019. All registered patients diagnosed with renal malformations (Q600, Q601, Q602, Q603, Q604, Q605, Q610, Q611, Q612, Q613, Q614, Q615, Q618, Q619, Q620, Q621, Q622, Q623, Q624, Q625, Q626, Q627, Q628, Q630, Q631, Q632, Q633, Q638, Q639), male genital malformations (Q530, Q531, Q532, Q539, Q540, Q541, Q542, Q543, Q544, Q548, Q549, Q550, Q551, Q552, Q553, Q554, Q555, Q556), and exstrophy-epispadias complex (Q640, Q641), according to the International Statistical Classification of Diseases and Health Problems 10th revision (ICD-10) (18) were included for analysis. No identifying variables were collected. We applied the diagnostic filters "confirmed new cases" and "confirmed repeated cases". Diagnostic impression and unspecified cases were excluded. With the purpose of quantifying the number of patients with these diagnoses, the function "people attended" was used, which includes each patient only once even if was attended multiple times during the time of the study.

The National Administrative Department of Statistics (Departamento Administrativo Nacional de Estadistica - DANE, by its Spanish acronym) is the entity responsible for collecting, processing, analysing official statistics in Colombia (19). The Vital Statistics Subsystem collects and processes information about all births and deaths that occur in the country. Live birth and death certificates are filled out by doctors, nurses, or authorized health personnel who attended the event in the institutions providing health services throughout the country. Live births are defined as a product of gestation after the expulsion or removal of the mother's body, regardless of the duration of the pregnancy. They must be able to breathe or give any other sign of life, such as heartbeat or umbilical cord pulsation (20). For the present study, we included all registered live births during 2015 - 2019 in each department of the country and discriminating by gender.

Geographical variables (latitude and longitude) of each department were extracted using the DANE geoportal. This tool collects the information of georeferenced data and allow access to geographic limits and official maps of the Colombian territory.

\section{Statistical analysis}

Cluster detection was performed using SaTScan v9.6 (21) for macOS (Satscan, 2018) to identify clusters with either high or low rates of medical assessments over time. The spatial-temporal statistical analysis using a Poisson probability model was conducted for each diagnostic group. In the case file, we included all people with the specified diagnoses and in the population file, the live births were added. Latitude and longitude coordinates were entered for each department. The study period started 01/01/2015 and ended 31/12/2019. Each analysis was run using a time aggregation of 1 year of length and the option scan for areas with high or low rates was selected. The results obtained were visualized in a map from Google Earth. Areas with the highest concentration of cases are shown in red. Meanwhile, clusters in blue show those municipalities below the average value assessed for the years analyzed.

\section{Results}

Between January 2015 and December 2019, a total of 26.726 patients with renal malformations, 19.149 patients with genital malformations, and 494 patients with exstrophy-epispadias complex in the outpatient clinic were assessed in Colombian territory.

In the case of renal malformations, space-time analysis identified one cluster with high provided health care concentration seen in the center of the country (Risaralda, Caldas, Quindío, Antioquia, Tolima, Valle del Cauca, Cundinamarca, Bogotá, D.C., and Huila) (Figure 1). Meanwhile northern regions close to the coast (Bolívar, Sucre, Magdalena, Córdoba, Cesar, La Guajira, and Norte de Santander) were identified as clusters with low rates of provided care regions.

Genital malformations spatial scan statistical analysis identified one cluster during the study time of shown in Figure 2 with a similar geographic distribution described above.

For cases with exstrophy-epispadias complex, a total of two clusters were identified (Figure 3). Regions in the north had lower registered assessments compared to the center of the country.

\section{Discussion}

Health care distribution demonstrate high cluster concentration of patients with renal malformations, male genital malformations and exstrophy-epispadias complex in highly dense urban areas mostly distributed in the center of the country. Other major cities do not show high concentration clusters. These results highlight unequitable distribution in the care of patients with congenital genitourinary malformations. Distance between home and hospitals, difficulty in obtaining medical care and type of healthcare provider might influence these results. (22) 
This has implications in patient prognosis, which in turn produce an increase cost to the health system. The identification of genitourinary malformation clusters can be used to optimize health care access (23).

Bladder exstrophy-epispadias complex is a severe abdominal midline malformation in which reconstructive procedures affect significantly patients' long-term quality of life. $(24,25)$ Increased risk of urinary incontinence and the need for multiples reinterventions are some of the consequences of failed primary bladder closure. (26) It has been demonstrated that subspecialty surgical training has a positive influence on successful results. (27) Gupta, et al (25) describe that UK experience in the centralization of these patients has resulted in experienced multidisciplinary teams, follow-up and psychological support. These, in turn, improved overall outcomes for patients. Our results suggests that patients living in remote areas of the country are less likely to receive specialized care in a timely manner what can affect their prognosis.

On the other hand, kidney congenital anomalies represent a significant cause of chronic kidney disease in children and young adults.(28,29) Previous studies have demonstrated that socioeconomic factors are related to end-stage renal disease due to difficult access to healthcare resources, including delayed referral. $(30,31)$ Our study does not provide information about the percentage of patients who develop chronic kidney failure. However, the areas of the country where we do not find clusters with high rates of medical attention are those with the greatest economic limitations, probably these patients are under deferred assessment. A study by Sanna-Cherchi, et al (32) followed a cohort of 312 children with renal and urinary tract anomalies until the age of 30 years. All patients with a diagnosis of posterior urethral valves had at least one surgical treatment, $35 \%$ of the children with solitary kidney and $22 \%$ of children with vesicoureteral reflux had ureteral reimplantation and all patients had been treated with prophylaxis for urinary tract infection for at least 1 year. This emphasizes the importance of an appropriate diagnosis and follow-up.

This is the first study to examine the spatial clusters of medical attention of genitourinary malformations in Colombia. Clustered areas need to be identified to facilitate the assessment of access to health care and design effective health interventions. In most cities, there are no subspecialists, and we cannot know how is the referral process and the waiting times. There are certain limitations to our study. Underreporting cases, methods of registration in certain areas, and differences in clinical practices or diagnostic techniques could have affected these results. Based on our findings, some recommendations can be proposed. It is necessary to collect more detailed information including waiting time to first specialized consultation as well as construct a system of tracking and reference of these patients.

\section{Conclusion}

Patients with genitourinary malformations have inequitable access to specialized health care which can delay surgical management and impact long-term outcomes that increase disability. There is a greater concentration of cases assessed in the center of the country, where most of pediatrics urologist, technology and hospitals are available.

\section{Declarations}

\section{Ethics approval and consent to participate}

“Not applicable"

Consent for publication

"Not applicable"

Availability of data and materials

The datasets generated during and/or analysed during the current study are available from the corresponding author on reasonable request.

Competing interests

"The authors declare that they have no competing interests"

\section{Funding}

None

\section{Authors' contributions}

"NF developed research idea. MP and JS, recovered data base information. IS analyzed and interpreted the patient's database. All authors read and approved the final manuscript." 
"Not applicable"

\section{References}

1. Cohen HL, Kravets F, Zucconi W, Ratani R, Shah S, Dougherty D. Congenital abnormalities of the genitourinary system. Seminars in Roentgenology. 2004 Apr;39(2):282-303.

2. dos Santos Junior ACS, de Miranda DM, Simões e Silva AC. Congenital anomalies of the kidney and urinary tract: An embryogenetic review. Birth Defects Research Part C: Embryo Today: Reviews. 2014 Dec;102(4):374-81.

3. Calderon-Margalit R, Golan E, Twig G, Leiba A, Tzur D, Afek A, et al. History of Childhood Kidney Disease and Risk of Adult End-Stage Renal Disease. New England Journal of Medicine. 2018 Feb;378(5):428-38.

4. Chu DI, Ehlayel AM, Ginsberg JP, Meyers KE, Benton M, Thomas M, et al. Kidney Outcomes and Hypertension in Survivors of Wilms Tumor: A Prospective Cohort Study. The Journal of Pediatrics. 2021 Mar;230:215-220.e1.

5. Mai CT, Isenburg JL, Canfield MA, Meyer RE, Correa A, Alverson CJ, et al. National population-based estimates for major birth defects, 2010-2014. Birth Defects Research. 2019 Nov 3;111(18):1420-35.

6. Stadler HS, Peters CA, Sturm RM, Baker LA, Best CJM, Bird VY, et al. Meeting report on the NIDDK/AUA Workshop on Congenital Anomalies of External Genitalia: challenges and opportunities for translational research. Journal of Pediatric Urology. 2020 Dec;16(6):791-804.

7. Global Health Estimates: Life expectancy and leading causes of death and disability.

8. Global Health Estimates 2020: Disease burden by Cause, Age, Sex, by Country and by Region, 2000-2019. Geneva; 2020.

9. Congenital anomalies. 2020.

10. Poenaru D, Pemberton J, Cameron BH. The burden of waiting: DALYs accrued from delayed access to pediatric surgery in Kenya and Canada. Journal of Pediatric Surgery. 2015 May;50(5):765-70.

11. Lauriot Dit Prevost A, Genin M, Occelli F, Priso R-H, Besson R, Lanier C, et al. Spatial analysis of hypospadias cases in northern France: taking clinical data into account. BMC Pediatrics. 2020 Dec 21;20(1):442.

12. Goungounga JA, Gaudart J, Colonna M, Giorgi R. Impact of socioeconomic inequalities on geographic disparities in cancer incidence: comparison of methods for spatial disease mapping. BMC Medical Research Methodology. 2016 Dec 12;16(1):136.

13. Kirby RS, Delmelle E, Eberth JM. Advances in spatial epidemiology and geographic information systems. Annals of Epidemiology. 2017 Jan;27(1):1-9.

14. Richardson S, Thomson A, Best N, Elliott P. Interpreting Posterior Relative Risk Estimates in Disease-Mapping Studies. Environmental Health Perspectives. 2004 Jun;112(9):1016-25.

15. DANE. Censo nacional de población y vivienda 2018: Resultados Colombia. Total nacional. 2018.

16. Departamento Administrativo Nacional de Estadística (DANE). Atlas estadistico 2012 [Internet]. 2012. Available from: https://geoportal.dane.gov.co/servicios/atlas-estadistico/

17. Ministerio de Salud. Preguntas frecuentes Registro Individual de Atención - RIPS [Internet]. 2015. p. 1-17. Available from: https://www.minsalud.gov.co/sites/rid/Lists/BibliotecaDigital/RIDE/DE/OT/FAQ-RIPS.pdf

18. World Health Organization. International statistical classification of diseases and related health problems. - 10th revision [Internet]. 2016. Available from: https://icd.who.int/browse10/Content/statichtml/ICD10Volume2_en_2016.pdf

19. DANE - Información para todos [Internet]. Available from: https://www.dane.gov.co/index.php/acerca-del-dane/informacioninstitucional/generalidades

20. DANE. Metodología de las estadísticas vitales [Internet]. 2020. Available from: https://www.dane.gov.co/files/investigaciones/fichas/poblacion/metodologia-eevv.pdf

21. Kulldorff M. Information Management Services, Inc. SaTScan@ v8.0: software for the spatial and space-time scan statistics [Internet]. Available from: https://www.google.com/search?

client=safari\&rls=en\&q=Kulldorff+M.+Information+Management+Services,+Inc.+SaTScan@+v8.0+:+software+for+the+spatial+and+spacetime+scan+statistics+(www.satscan.org\&ie=UTF-8\&oe=UTF-8

22. Padilla C, Raffray M, Pladys A, Vigneau C, Bayat S. Geographic Variations in the Risk of Emergency First Dialysis for Patients with End Stage Renal Disease in the Bretagne Region, France. International Journal of Environmental Research and Public Health. 2018 Dec 21;16(1):18.

23. Avilés LA, Alvelo-Maldonado L, Padró-Mojica I, Seguinot J, Jorge JC. Risk factors, prevalence trend, and clustering of hypospadias cases in Puerto Rico. Journal of Pediatric Urology. 2014 Dec;10(6):1076-82. 
24. Jayachandran D, Bythell M, Platt MW, Rankin J. Register Based Study of Bladder Exstrophy-Epispadias Complex: Prevalence, Associated Anomalies, Prenatal Diagnosis and Survival. Journal of Urology. 2011 Nov;186(5):2056-61.

25. Gupta AD, Goel SK, Woodhouse CRJ, Wood D. Examining long-term outcomes of bladder exstrophy: a 20-year follow-up. BJU International. 2014 Jan;113(1):137-41.

26. Davis R, Maruf M, Dunn E, DiCarlo H, Gearhart JP. The role of anatomic pelvic dissection in the successful closure of bladder exstrophy: an aid to success. Journal of Pediatric Urology. 2019 Oct;15(5):559.e1-559.e7.

27. Baradaran N, Cervellione RM, Orosco R, Trock BJ, Mathews RI, Gearhart JP. Effect of Failed Initial Closure on Bladder Growth in Children With Bladder Exstrophy. Journal of Urology. 2011 Oct;186(4):1450-4.

28. Occelli F, Deram A, Génin M, Noël C, Cuny D, Glowacki F. Mapping End-Stage Renal Disease (ESRD): Spatial Variations on Small Area Level in Northern France, and Association with Deprivation. Reboldi G, editor. PLoS ONE. 2014 Nov 3;9(11):e110132.

29. dos Santos Junior ACS, de Miranda DM, Simões e Silva AC. Congenital anomalies of the kidney and urinary tract: An embryogenetic review. Birth Defects Research Part C: Embryo Today: Reviews. 2014 Dec;102(4):374-81.

30. Kihal-Talantikite W, Deguen S, Padilla C, Siebert M, Couchoud C, Vigneau C, et al. Spatial distribution of end-stage renal disease (ESRD) and social inequalities in mixed urban and rural areas: a study in the Bretagne administrative region of France. Clinical Kidney Journal. 2015 Feb 1;8(1):7-13.

31. Volkova N, McClellan W, Klein M, Flanders D, Kleinbaum D, Soucie JM, et al. Neighborhood Poverty and Racial Differences in ESRD Incidence. Journal of the American Society of Nephrology. 2008 Feb;19(2):356-64.

32. Sanna-Cherchi S, Ravani P, Corbani V, Parodi S, Haupt R, Piaggio G, et al. Renal outcome in patients with congenital anomalies of the kidney and urinary tract. Kidney International. 2009 Sep;76(5):528-33.

\section{Figures}

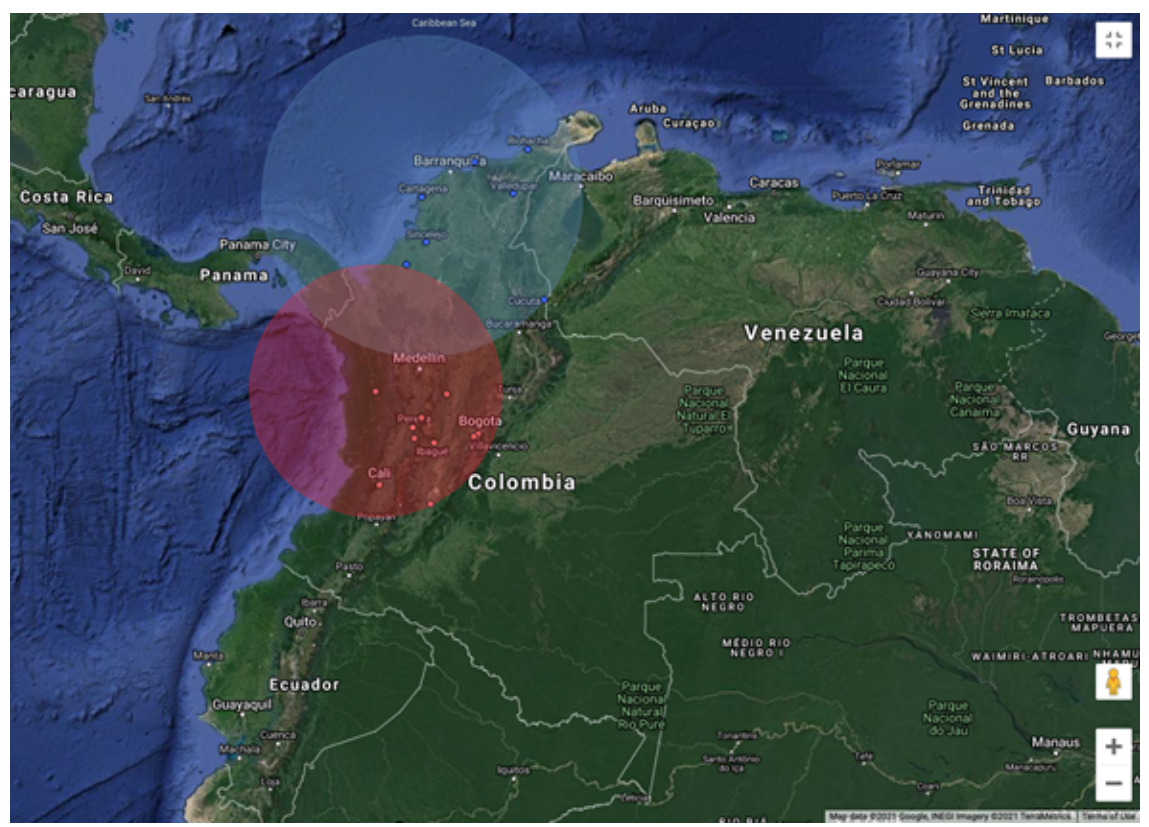

\section{Figure 1}

Spatial-temporal analysis of renal malformations. Identified hypospadias clusters with increasing trends in cases assessed (red) and clusters with decreasing trends (blue). 


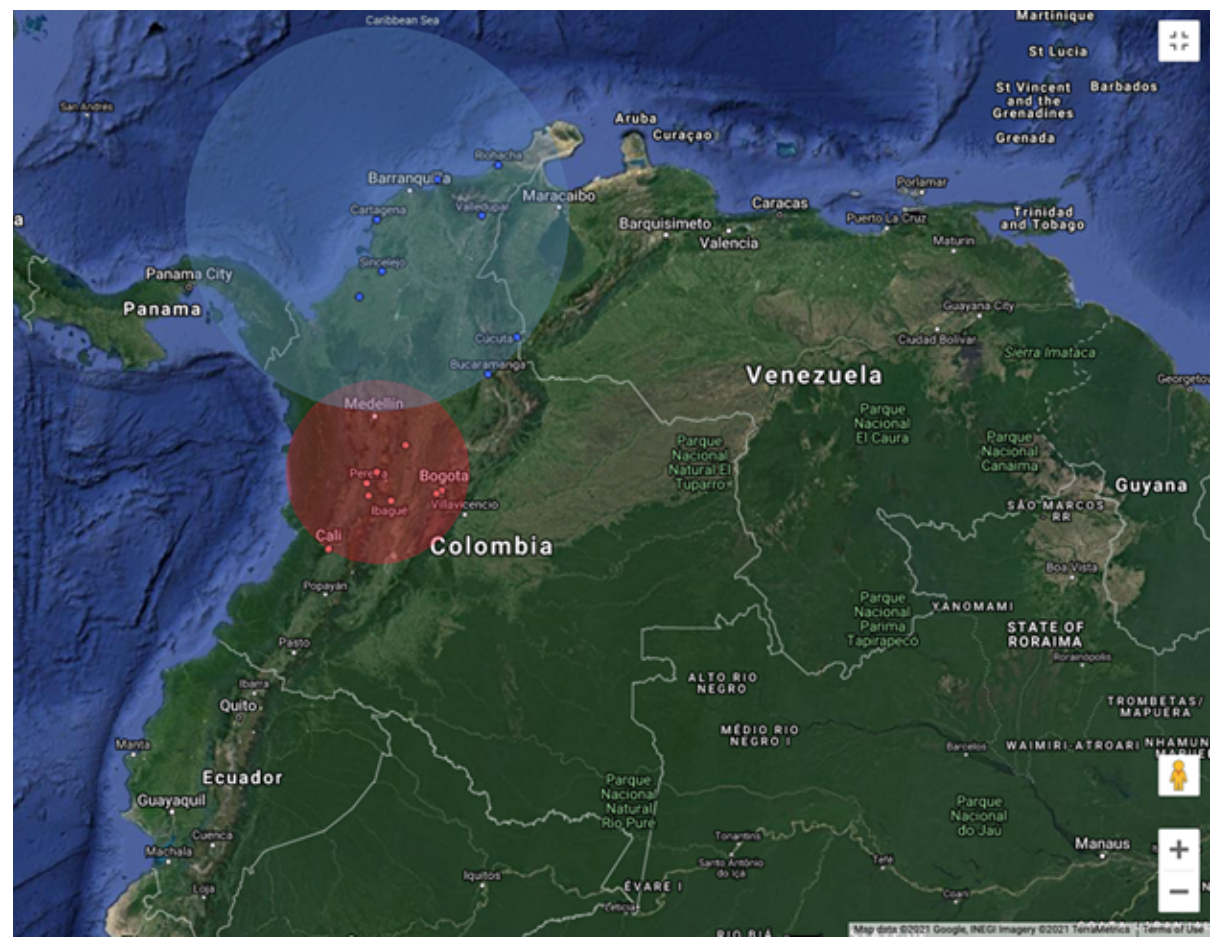

\section{Figure 2}

Spatial-temporal analysis of male genital malformations.

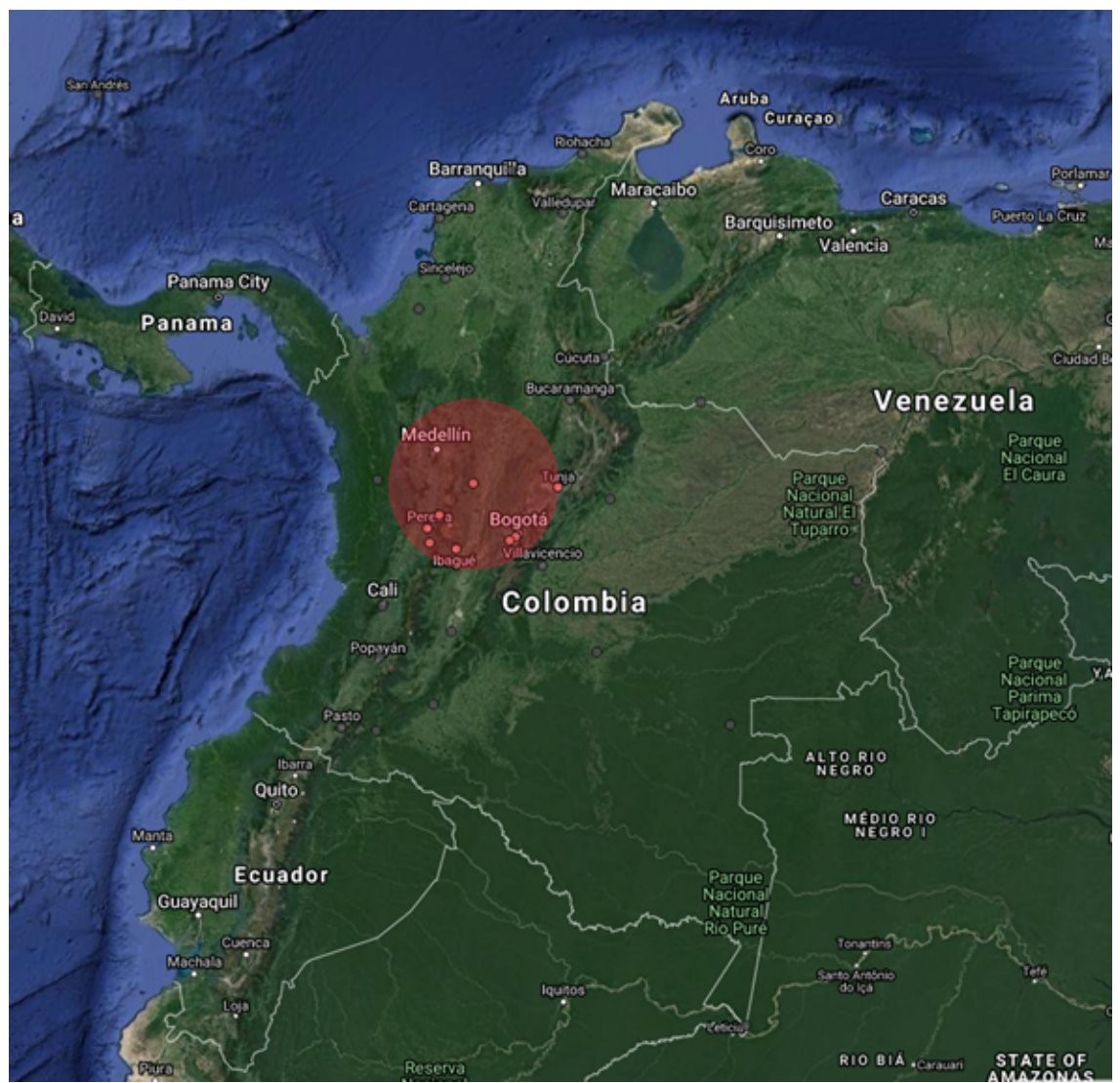

\section{Figure 3}

Spatial-temporal analysis of Exstrophy-epispadias complex 